I Pontifícia Universidade Católica do Rio de Janeiro (PUC-Rio), Laboratório de Antropologia do Consumo, Rio de Janeiro, RJ, Brasil liviabstein@gmail.com II Pontifícia Universidade Católica do Rio de Janeiro (PUC-Rio), Rio de Janeiro, RJ, Brasil jcsrodri@terra.com.br

Lívia Boechenstein' José Carlos Rodrigues"

\title{
OS GRANDS MAGASINS, PROTAGONISMO FEMININO E MAGIA NO PARAÍSO DO CONSUMO
}

Rocha, Everardo; Frid, Marina \& Corbo, William. (20I6).

O paraíso do consumo: Émile Zola, a magia e os grandes

magazines. Rio de Janeiro: Mauad X/Editora PUC-Rio.

Em um profundo mergulho na obra 0 paraíso das damas, de Émile Zola (2008), publicada pela primeira vez em I883, Everardo Rocha, Marina Frid e Wiliam Corbo capturam o leitor e o levam a conhecer as engrenagens e os fascínios que possibilitaram o surgimento e a perenidade de $O$ paraíso do consumo. O título é o apelido dado pelos autores aos grandes centros comerciais que parecem remeter seus frequentadores a um universo de sonho. Suas páginas apresentam ao leitor os encantos do mundo das lojas de departamentos e os ritmos acelerados das grandes cidades europeias, principalmente Paris, onde se passa o romance, na segunda metade do século XIX. O livro aqui resenhado aborda o consumo a partir da obra de Zola sobre os grands magasins, dando especial atenção aos pilares que possibilitaram a estruturação das lojas de departamentos e seu indubitável sucesso comercial.

Sempre aliando antropologia do consumo com o que é descrito no romance de Zola, os capítulos seguem uma ordem lógica de enriquecimento teórico que auxilia o leitor na compreensão do consumo como fenômeno social. Essa abordagem antropológica é feita como uma retomada teórica que se inicia com os primeiros autores das ciências sociais que trabalharam o consumo, afastando-se da ênfase e do privilégio que historicamente foram atribuídos à produção. Nesse ponto reside um dos méritos do livro: resgatar obras fundamentais que abordaram o consumo e apontar para a desatenção relativa de que foi alvo essa ponta da cadeia produtiva. 
Não é preciso que o leitor tenha conhecimento prévio da obra de Zola para uma boa compreensão do texto, pois os autores elaboram uma eficiente contextualização e introdução ao romance. Também apresentam um importante índice de personagens, além de um quadro histórico-informativo com as datas relevantes para entendimento da linha do tempo das teorias apresentadas. Ademais, ao final de cada capítulo, há uma seleção de trechos relevantes da publicação original, traduzidos para o português, fragmentos que ilustram aquilo que está sendo apresentado pela perspectiva das ciências sociais.

A descrição minuciosa feita de forma bastante densa por Zola é típica de seu estilo literário, o naturalismo francês. Em geral, a literatura de tal escola é bastante realista, factual, e costuma se deter na descrição de rotinas e hábitos dos grupos sociais sobre os quais discorre. Na pesquisa realizada para verificar em que condições Zola escrevera $O$ paraíso das damas, foi possível encontrar registros de que o escritor de fato havia circulado pelos grands magasins de sua época. Conviveu com os trabalhadores que frequentavam os bastidores da esfera de produção, em uma rotina árdua e fabril, circulou entre os vendedores que atendiam a burguesia e esteve entre funcionários de escritórios e demais instâncias administrativas. Esse extenso trabalho de campo revela aspectos verdadeiramente etnográficos, apesar de a disciplina não estar ainda plenamente formatada na época em que o romance era gestado. Zola, no entanto, foi exemplar etnógrafo: mudou de endereço, folheou anotações comerciais, conversou com empresários e com setores produtivos, esteve com os fregueses, alimentou-se em refeitórios de operários, observou os estilos de vida, os modos e os hábitos das classes com as quais conviveu para a preparação e realização da obra.

o paraíso do consumo é, então, um livro sobre outro livro - mas sobretudo a partir deste. No detido estudo da obra de Zola, os autores exploram o contexto que precedeu o surgimento desse novo tipo de comércio, os significados e consequências gerados pelo grand magasin. Tomam-no como personagem principal, não como mero pano de fundo da obra. O objetivo: empreender minuciosa investigação sobre os fatores que antecederam as lojas de departamentos, seus impactos sobre a vida social, as inovações que trouxeram à prática comercial e às inéditas formas de oferecer produtos.

A obra também tematiza de maneira instigante a gestação do sistema de modas, o surgimento de novas alternativas de sociabilidade e as mudanças nas dinâmicas de produção e de consumo - aspectos que hoje conhecemos bem, pois se refletem de forma quase inalterada desde o século XIX. Au bonheur des dames, título original da publicação de Zola, é entendido, portanto, não como simples romance, mas como um documento de grande valor histórico, que apresenta em meio às tramas dos personagens um registro capaz de revelar o espírito do seu tempo e as mudanças tecnológicas que revolucionaram o quotidiano de então. 
Para entender o que antecede a chegada das lojas de departamentos e seu decorrente sucesso, é preciso conhecer o que se passava histórica e socialmente nos locais em que esses grandes centros apareceram. Em Paris, por exemplo, as galerias e passagens reuniam uma série de lojas, e as atividades de consumo se davam circulando no comércio de rua. Esse aspecto constituía um problema especial para as mulheres de classe alta da época: não era uma boa opção, para uma mulher que não pertencesse ao operariado, andar desacompanhada (de marido, pai ou irmão) pelas ruas, pois as que frequentavam esse tipo de ambiente não eram vistas positivamente pela moral vigorante.

À parte isso, Paris, bem como as demais grandes cidades europeias, vivia uma relativa ascensão: inchaço populacional causado pelo intenso êxodo rural de jovens que deixavam o campo em busca de melhores salários e condições de vida nas indústrias, progres so tecnológico, expansão dos veículos de comunicação, maior liberdade de imprensa, novos meios de transporte, nenhuma guerra impactante ou crise econômica que fosse capaz de devastar a população de seu trabalho de aprimoramento geral e contínuo.

As lojas de departamentos chegam como reflexo desse cenário de prosperidade. Além disso, também amenizavam alguns problemas existentes nas formas de comércio conhecidas até então: produtos nas lojas que não podiam ser tocados, que não tinham preços expostos e uma série de outras dificuldades. Não havia épocas espe- ciais para aumento de vendas nem promoções. As vitrinas apenas expunham os produtos objetivamente, quando o faziam. Os grands magasins trazem novas estratégias de venda. Surgem para transformar a experiência de consumo e acabam por provocar profundas mudanças na própria sociedade (Rappaport, 2004).

As mulheres foram a principal categoria social a passar por modificações, tanto as de camadas mais baixas ou operárias quanto as burguesas. As que trabalhavam tinham anteriormente poucas opções de emprego fora do ambiente fabril. As lojas de departamentos representam um novo campo, de alta empregabilidade, que transforma mulheres da classe trabalhadora em vendedoras de departamentos que lidavam diretamente com fregueses, não apenas operárias fabris. Para tal, elas tiveram que se reinventar: mudar o vestuário, as maneiras, a instrução - elementos que as denunciavam como outsiders entre as classes mais abastadas.

As mulheres compunham a maior parte da força de trabalho dos grands magasins. Também eram maioria absoluta entre o público consumidor. As burguesas, que não eram bem-vistas circulando em espaços públicos, puderam pela primeira vez ir além dos locais em que sua circulação era permitida, como o ambiente doméstico ou as igrejas. Donas de casa, as mulheres de classes mais altas habitavam agora também as seções desses grandes centros comerciais, que têm algo de sagrado em sua conotação. Lá, elas estavam cercadas daquilo que po- 
I076

deriam desejar, rodeadas por atendentes a lhes prover as demandas: restaurantes, salas de descanso, biblioteca, lojas de tecidos para todos os tipos de vestimentas, serviço de costura, cafés, salões de música e mesmo exposições e palestras. A partir desse protagonismo dado inicialmente por esses novos âmbitos sociais é que as mulheres obtêm, segundo os autores, a força e o apoio necessários para ambicionar novas conquistas em novos espaços: as lojas de departamentos foram essenciais para a conquista do direito de voto e para possibilitar a atividade política feminina (Leach, I984).

As técnicas para atrair e reter os consumidores em seus ambientes pelo máximo de tempo possível transformaram a sociedade, posto que trouxeram novas oportunidades e um novo tipo de trabalho. Por exemplo, algumas categorias de operários não mais são marginalizadas nos guetos, mas convivem e circulam entre burgueses, desenvolvendo gostos parecidos, hábitos de consumo similares, aprimorando-se na educação e nos investimentos culturais. O paraíso do consumo evidencia então o surgimento de uma classe média atrelado à expansão do consumo e do poder de compra.

Esses espaços comerciais possibilitaram novas formas de consumo e inovaram em técnicas e estratégias de promoção e marketing que vemos até os dias atuais. Os chamados shopping holidays foram também mais uma invenção do grande catálogo de artifícios de aumento de vendas trazidos pelos grands magasins. As vitrinas que expunham o que era desejável que se possuísse em determinadas épocas não mais precisavam ser realistas. Passaram a ser espaços dedicados ao devaneio, aos sonhos de consumir, aos desejos independentes de restrições práticas.

A partir de um romance de inspiração etnográfica, escrito durante o século XIX, Rocha, Frid \& Corbo foram capazes de analisar detalhadamente as profundas mudanças ocorridas em diversos aspectos da vida social, uma vez instaladas as lojas de departamentos. O paraíso do consumo, contudo, não é obra apenas sobre transformações. Nela as permanências também encontram lugar. Sua leitura é essencial para compreender que o sentimento de um mundo submetido a incessantes transformações é também uma característica permanente da modernidade. E que aquilo que enxergamos como as inovações "mais recentes" pode perfeitamente estar prenunciado nos clássicos da literatura.

Recebida em I6/2/20I8 | Aprovada em I/6/20I 8 


\section{REFERÊNCIAS BIBLIOGRÁFICAS}

Leach, William. (I984). Transformations in a culture of consumption: women and department stores. The Journal of American History, 7I/2, p. 319-342.

Rappaport, Erika. (2004). Uma nova era de compras: a promoção do prazer feminino no West End Londrino, I909-I9I4. In: Charney, Leo \& Schartz, Vanessa R. (orgs.). O cinema e a invenção da vida moderna. São Paulo: Cosac Naify, p. I57-I84.

Zola, Émile. (2008) [I883]. O paraíso das damas. Tradução de Joana Canêdo. São Paulo: Estação Liberdade.

Lívia Boeschenstein é doutoranda e mestre em comunicação pelo Programa de Pós-Graduação em Comunicação da PUC-Rio.

José Carlos Rodrigues é doutor em antropologia pela Université Paris 7, professor do Programa de PósGraduação em Comunicação da PUC-Rio e professor titular do Departamento de Antropologia da UFF. É autor dos livros Tabu do corpo (I 979), Antropologia e comunicação (I989), O corpo na história (I999) e Imaginários e dramas sociais: estudos de significação (20I5). 